\title{
Examines the role of human factors in the severity of traffic accidents in urban areas, with an emphasis on motorcyclists (Case Study: Eslamshahr - Saveh Road)
}

\author{
Ali Reza Shir Mohammad KARIMI ${ }^{1,{ }^{*}}$, Mohammad Javad KHOSRAVI ${ }^{2}$, Sahba GolChINFAR ${ }^{3}$ \\ ${ }^{1}$ Master planning of transport and traffic, Islamic Azad University, South Tehran, Tehran, \\ Iran \\ ${ }^{2}$ Master of Urban Planning, Urban Planning, Tehran University, Tehran, Iran \\ ${ }^{3}$ Master of Urban Planning, Urban Planning, University of Science and Technology, Iran
}

\begin{abstract}
Every year 1.2 million people worldwide lose their lives due to traffic accidents and more than 50 million others are injured. Ninety percent of deaths caused by traffic accidents involving low or middle income countries. Statistics show that in Iran. After cardiovascular diseases, traffic accidents are the leading cause of death in all age groups and is the first cause of death in those under forty years. Pedestrians, cyclists, motorcyclists, drivers and passengers in cars and other vehicles, are at greater risk of high-risk road user as they remembered. Among the most important role in preventing accidents drivers in this traffic, so that a driver unsafe driving not only their lives, but the lives of others in danger. Amending and enforcing laws and traffic regulations, creating safe way and promote a safety culture among the factors reducing traffic accidents are statistics. Given the importance of this paper is descriptive - analytic method has been tried, the role of human factors in the severity of traffic accidents in cities, with an emphasis on motorcyclists in the city of Eslamshahr Saveh Road to be addressed. Research findings show an increase in the number of vehicles, facilitating increased sales of motorcycles, young population and special charm motorcycles over the past decade, production, sale and use of motorcycles in the country has an increasing trend. And consequently the number of fatal crashes, injury and damage to the motorcycle riders were guilty, relative to the total vehicle accidents, rising substantially shows.
\end{abstract}

Keyword: motorcycle, laws, accidents, violations, Eslamshahr - Saveh Road

\section{Introduction}

World, including Iran motorcycles are part of the traffic flow and the safety of other road user's attention as it should be, Safety motorcycle riders also be considered. Disregard for the law and violations of motorcyclists is a normal behavior, riding a Motorcycle with actions and violations that do. In addition to the loss of civil liberties leads to insecurity and social security have been playing and still have no plan and failed to stonewall them. Whether these offenses arising from non-compliance with relevant laws and regulations. Today, this community has come in the form of an acute dilemma. Passing pedestrians, disregard for traffic signs, running red lights, entry, non-use of helmets, entrance to the highway, dangerous driving and moves the offense. Abuse motorcyclists who do not know them, misconduct has become a tradition for them. What is important for police enforcement of traffic laws and regulations by motorcycle riders? Police believe: The number of violations by motorcyclists is high and should be a fundamental choice to ponder it. Motorcyclist's violations in the field of information and culture must be done the other hand, people should

* - Corresponding Author 
also assist the police in this regard. Several years of news, interviews and various reports published motorcyclists and violations, and the earth and time of these drivers lawless people cry but could not cross the old wound treatment violations and lawlessness are motorcyclists. When motorcycle helmet is not even close to their health, and their lives are of no value to them, whether it be expected to care about the lives of others? In advanced countries have motorcycle clothing, motorcycle equipped with ABS brakes and other possibilities, in our country, not only is this stuff is a joke, but the laws are ignored by the people. Most motorcyclists do not have a helmet or hung from the steering motor and the police as soon as it showed a hint. Eslamshahr, through the Tehran-Saveh, with the provinces of West and South West of the country's highway and railway axis of south-west at Isfahan, Yazd and Kerman, on the one hand and on the other hand is Lore Stan and Khuzestan. Saveh Road is one of the main roads with heavy traffic and heavy half.

\section{The advantages and disadvantages of the use of motorcycles:}

\subsection{Switching is Easy with motorcycles:}

The development of cities in terms of population, area and production of vehicles by manufacturers and to ban old cars from the transportation network is leading to worsening traffic problem. As far as some parts of major cities have seen a new phenomenon of urban transport such as passenger and cargo handling individually or organized by motorcycle riders are like courier agencies. Especially in Eslamshahr with restrictions for taxis within the market, this system immediately as an alternative system proposed in this area. According to available statistics, more than half of motorcycle drivers working in that system are also under the age of 35 years.

\subsection{Limitations and disadvantages of motorcycles and motorcycle equipment to car}

Motorcycles than cars with smaller dimensions and less daylight than the car is diagnosed. And when it is exposed to the risk of occupant injury in the event of an accident increases. The visibility of motorcycles at night to have a front light and a rear light is less. The same justice for car drivers at night is difficult to guess the correct distance and speed of motorcycles. Helmet use has some disadvantages in addition to advantages such as: Complication for users in the tropics, especially at low speeds, which reduces the freezing cold with steam oral hearing and eye protection helmets reduce the vision is. Tips that motorcyclists should be observed that when a strong wind blows cross or motorcycle rider wants to overtake trucks and trailers heavy vehicle like the wind to slow down in front of a cross wind, to control the motorcycle in timely rainfall and reduced speed when driving a motorcycle through the flood with heavy gear. In bad weather conditions and dust needed a safe distance from the vehicle in front and rear to maintain a state of hazy atmosphere to see the depth of one hundred meters from use fog lights, During the winter, especially of black ice in sub-zero temperatures when rainfall occurs, reduce vehicle speed to a minimum. When motorcycle riders must ride in safety equipment, including helmets, clothes, shoes, gloves, goggles and knee pads motorcycle use as a risk factor down.

\section{Comparison demand for motorcycles in Iran and other countries}

In Japan, the number of two-wheel vehicles begun in 1970 will be significantly higher in 1990 to 15 million units. This increase trend is now more than 60 million two-wheeled vehicles (motorized, non-motorized) is reached. The motorcycle ownership has been remarkable during this period so that the number of motorcycle owners from 5.8 million in 1977 to 3.11 million in 1982 has increased. In Malaysia in 1997, more than 4,328,997 units of motorcycle traffic, of which about $51 \%$ of all vehicles registered in that country were involved. According to the police report in 1998, the number of six thousand and losses due to accidents in 1997, 304 motorcyclists more than 60 percent of the three thousand and 778 
people were involved. And from 53 thousand 512 accidents occurred in about 67 percent of the 35 thousand and 960 motorcycle riders were to blame for death of about 2/49 of those killed in motorcycle accidents cause head injury or brain injury was. In our country during the past decade, production, sale and use of motorcycles to facilitate the sale procedures of young people had an increasing rate. So that virtually from 1379 onwards, demand or use of motorcycles gained momentum and just over 3 million units were entered at the same time.

\section{Analysis of the test results (power) engine power (Forum) motorcycles}

To measure the strength (power) Motorcycle Test as "motorcycles - pure power - the driving force test methods" is performed. Standard test method according to Iran National Standard 6653, which is based on the International Standard ISO 4106 was developed, the following is a summary of its performance in this test method, the driving force (engine) motorcycle, and the case is considered separately and disassembled. A series of parts $(\mathrm{Eg}$, exhaust) and electrification systems are disassembled motorcycle also placed on the device. In this test temperature, humidity and oil temperature and engine temperature should be standard at the time of the test shall be between 10 and 45 degrees. The purpose of this test is to obtain the maximum net power engine on the chassis dynamometer at the end of the crankshaft motorcycle and engine speed corresponding to it. The specific fuel consumption, which is the amount of fuel consumed per unit of output per hour can be achieved in this test. Remote engine rpm 3500 to the highest motorcycle far away they can finally drop is usually "pm9000 out. The test will give us the following information:

1. The motorcycle according $\mathrm{kW}$ maximum power

2. Engine speed with maximum power occurs by RPM

3. The maximum engine torque based on engine speed $\mathrm{Nm}$ and maximum torque occurs by RPM

4. The specific fuel consumption at maximum power and maximum torque of grams per $\mathrm{kWh}$ in the following tables strength of motorcycles based on engine size, presented the following results were based on more than 600 models of motorcycles is obtained.

\section{Introduce the studied area}

Eslamshahr Figure 1 in the central plateau region between the North West and geographical location "30," 22, "51 and" 0, "10," 51 'east longitude and 30 "," 42, "34 and" 30 ," 27 "35 'north latitude and on the alluvial flood and current alluvial fan flooding the southern slopes of Alborz is centrally located. Area of over 278 square kilometers (1.7 percent of Tehran province) occupies the (governor Eslamshahr, 1390). Eslamshahr on one of the main roads south of Tehran, Tehran-Saveh the communication center and the railway line in $22 \mathrm{~km}$ to the South West of the capital, Tehran, Qom is located (master plan Eslamshahr, along Consulting Engineers, 1364, Part II: 1). In the past, due to the proximity of the village Qasmabad with Saveh Road, Eslamshahr or Qasmabad knew the name of the royal Qasmabad and later its name was Shadshhr. The town has three divisions City (Eslamshahr, Chahardangeh, Ahmedabad Exchequer) Eslamshahr is the center of the city. 


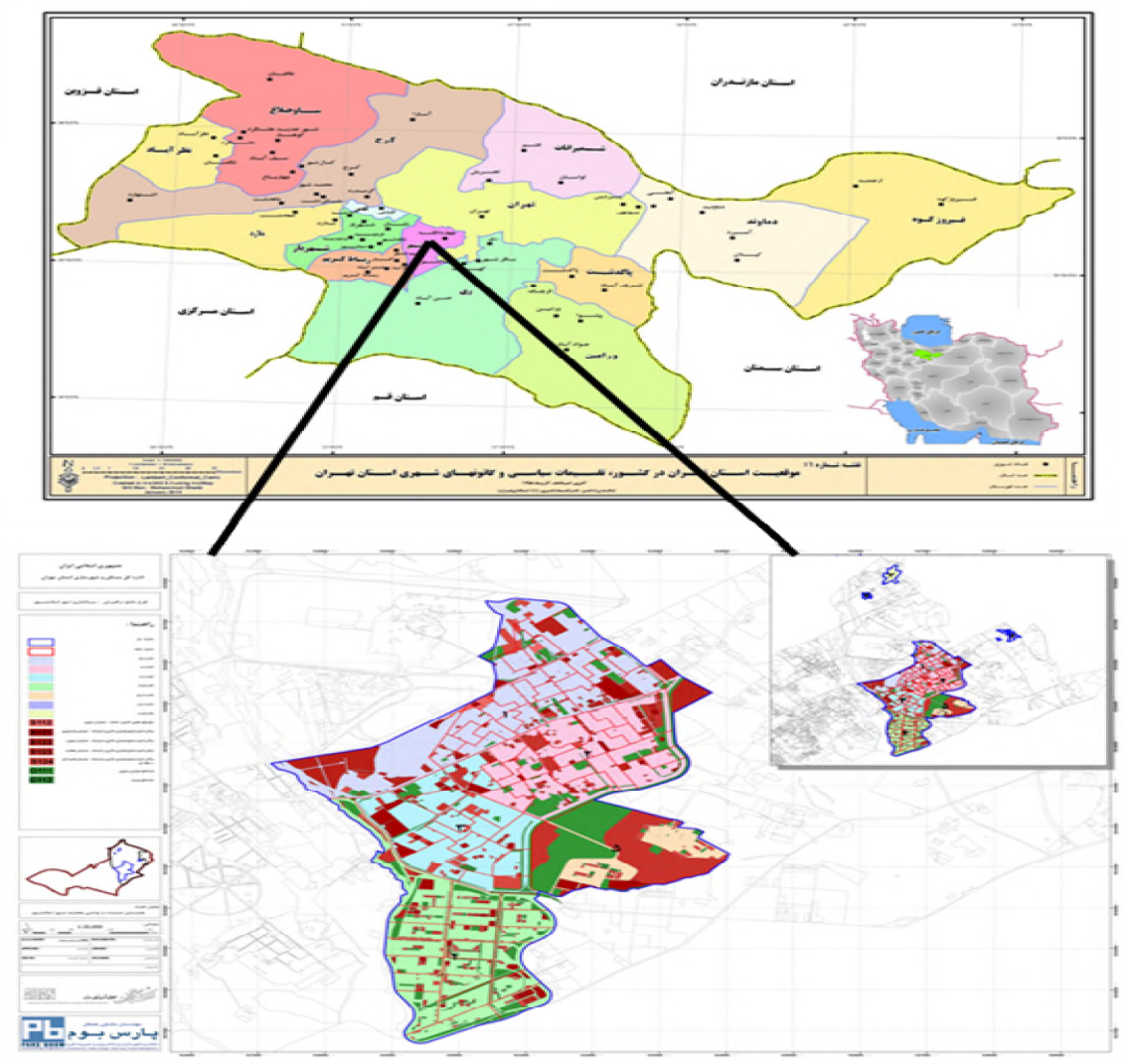

Figure 1: Map and location City Eslamshahr

\subsection{Characteristics of population in Eslamshahr}

In general, the city population changes in different periods Census Eslamshahr are as follows:

Table 1: Status Eslamshahr of the city's population from 1345 to 1390

\begin{tabular}{|c|c|c|c|c|}
\hline Growth rate \% & $\begin{array}{c}\text { Eslamshahr } \\
\text { \%growth rate }\end{array}$ & $\begin{array}{c}\text { Share of the \% } \\
\text { total population }\end{array}$ & $\begin{array}{c}\text { The absolute } \\
\text { number of } \\
\text { population }\end{array}$ & Year \\
\hline 3.1 & 7.66 & 0.0039 & 1006 & $\mathbf{1 3 4 5}$ \\
\hline 2.7 & 47.87 & 0.43 & 50292 & $\mathbf{1 3 5 5}$ \\
\hline 3.9 & 15.56 & 0.43 & 215129 & $\mathbf{1 3 6 5}$ \\
\hline 1.96 & 2.12 & 0.44 & 265460 & $\mathbf{1 3 7 5}$ \\
\hline 1.5 & 3 & 0.51 & 357389 & $\mathbf{1 3 8 5}$ \\
\hline 1.29 & 1.66 & 0.55 & 389102 & $\mathbf{1 3 9 0}$ \\
\hline
\end{tabular}

Source: (General Population and Housing Census Statistical Center of Iran 45-90) 


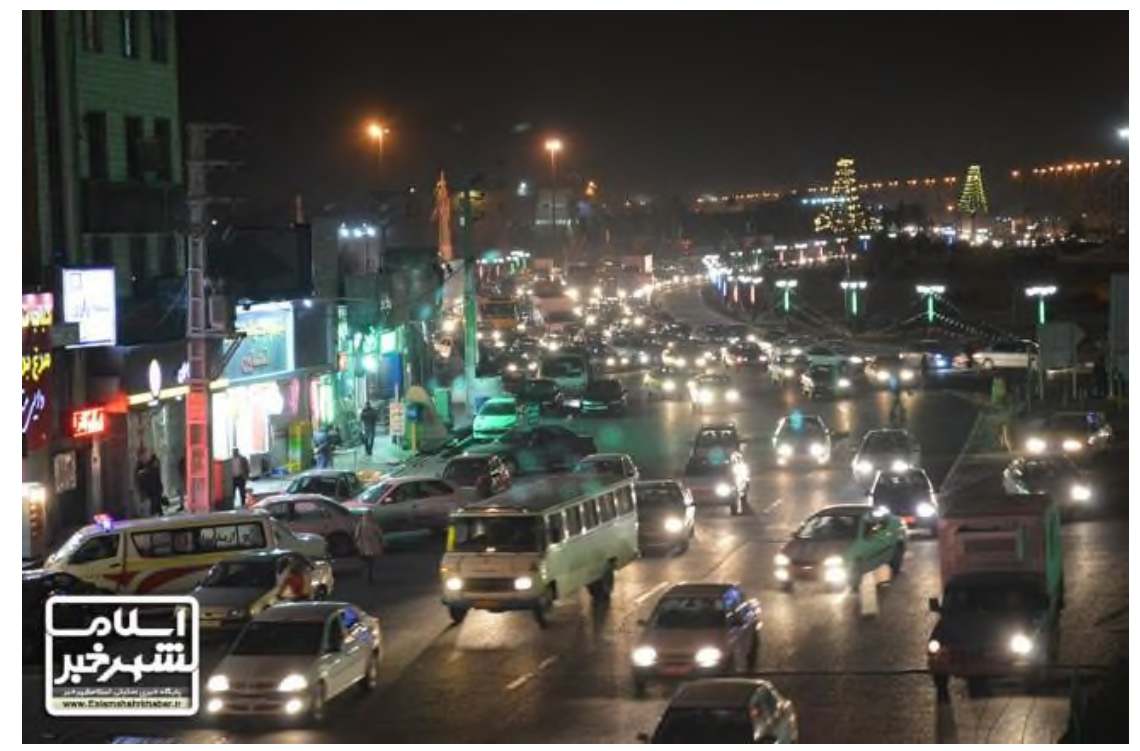

Image 1: A view of the heavy traffic on Eslamshahr

\section{The most important problems in society by Rakbin motorcycles}

As mentioned before, however, this stratum of society have caused many problems in society, that is no secret, tragic crashes we see every day that in many cases one side is a motorcycle accident. Unfortunately, all people, both on foot and are afraid of these people, to anyone ever had the feeling of security is not even on the sidewalk. In traffic at a red light motorcycles with a car there is a risk of collision. But who is to blame in this regard: With a view on whether the problems have been identified and analyzed, which ultimately are summarized. Riders motorcycle accidents, analytical information on Eslamshahr - Saveh Road traffic police in the first six months of the year 90 :

Table 2: Type of deal

\begin{tabular}{|c|c|c|c|}
\hline The share of total & Number & The subject & Row \\
\hline $90.7 \%$ & 92 & Vehicle collision with motorcycle & $\mathbf{1}$ \\
\hline $2.9 \%$ & 6 & Motorcycle collided with a motorcycle & $\mathbf{2}$ \\
\hline $6.4 \%$ & 12 & Motorcycle collision with pedestrian & $\mathbf{3}$ \\
\hline $0.0 \%$ & 0 & Bike motorcycle collision & $\mathbf{4}$ \\
\hline $0.0 \%$ & 0 & Leaving the track and overturned & $\mathbf{5}$ \\
\hline $0.0 \%$ & 0 & other & $\mathbf{6}$ \\
\hline $100.0 \%$ & 110 & Total & $\mathbf{7}$ \\
\hline
\end{tabular}

Table 3: The main cause of accidents

\begin{tabular}{|c|c|c|c|}
\hline The share of total & Number & The subject & Row \\
\hline $46.6 \%$ & 94 & No yield sign & $\mathbf{1}$ \\
\hline $17.2 \%$ & 34 & Disregarding forward & $\mathbf{2}$ \\
\hline $12.3 \%$ & 23 & Tailgating & $\mathbf{3}$ \\
\hline $13.7 \%$ & 27 & Rapidly change directions & $\mathbf{4}$ \\
\hline $1.5 \%$ & 4 & Running red lights & $\mathbf{5}$ \\
\hline $4.4 \%$ & 8 & Crossing the prohibited place & $\mathbf{6}$ \\
\hline $2.0 \%$ & 4 & Inability to control the & $\mathbf{7}$ \\
\hline $2.5 \%$ & 6 & other & $\mathbf{8}$ \\
\hline $100.0 \%$ & 190 & Total & $\mathbf{9}$ \\
\hline
\end{tabular}


Table 4: The culprit in the accident

\begin{tabular}{|c|c|c|c|}
\hline The share of total & Number & the subject & Row \\
\hline $66.2 \%$ & 135 & The motorcycle driver & $\mathbf{1}$ \\
\hline $24.0 \%$ & 49 & Person & $\mathbf{2}$ \\
\hline $9.8 \%$ & 20 & other & $\mathbf{3}$ \\
\hline $100.0 \%$ & 204 & Total & $\mathbf{4}$ \\
\hline
\end{tabular}

Table 5: Location of accident

\begin{tabular}{|c|c|c|c|}
\hline $\begin{array}{c}\text { The share of } \\
\text { total }\end{array}$ & Number & The subject & Row \\
\hline $25.5 \%$ & 52 & Square & $\mathbf{1}$ \\
\hline $55.9 \%$ & 114 & Intersection & $\mathbf{2}$ \\
\hline$-5.9 \%$ & 12 & Highway & $\mathbf{3}$ \\
\hline $0.0 \%$ & 0 & Hotline & $\mathbf{4}$ \\
\hline $13.7 \%$ & 28 & Straight path & $\mathbf{5}$ \\
\hline $0.0 \%$ & 0 & other & $\mathbf{6}$ \\
\hline $100.0 \%$ & 204 & Total & $\mathbf{7}$ \\
\hline
\end{tabular}

Table 6: Situation, the use of helmets

\begin{tabular}{|c|c|c|c|}
\hline Non-use of helmets & The use of caps & The subject & Row \\
\hline $35 \%$ & $65 \%$ & The motorcycle driver & 1 \\
\hline $77 \%$ & $23 \%$ & Sit back motorcycle & 2 \\
\hline
\end{tabular}

Table 7: The number of casualties and victims

\begin{tabular}{|c|c|c|r|}
\hline $\begin{array}{c}\text { The number of } \\
\text { victims }\end{array}$ & $\begin{array}{c}\text { The number } \\
\text { of injured }\end{array}$ & The subject & Row \\
\hline 0 & 41 & For bikers & 1 \\
\hline 0 & 5 & Sit back motorcycle & 2 \\
\hline
\end{tabular}

Statistics of road accidents in Eslamshahr - Saveh Road on the type of vehicle at fault in the accident in the first six months of 1391.

Table 8: Type motorcycle collision

\begin{tabular}{|c|c|c|c|}
\hline The share of total & Number & The subject & Row \\
\hline $89.55 \%$ & 18 & Vehicle collision with motorcycle & $\mathbf{1}$ \\
\hline $3.48 \%$ & 7 & Motorcycle collision with motorcycle & $\mathbf{2}$ \\
\hline $0.99 \%$ & 12 & Motorcycle collision with pedestrian & $\mathbf{3}$ \\
\hline $0.0 \%$ & 2 & Motorcycle collision with bicycle & $\mathbf{4}$ \\
\hline $0.0 \%$ & 0 & Leaving the track and overturned & $\mathbf{5}$ \\
\hline $0.0 \%$ & 0 & other & $\mathbf{6}$ \\
\hline $100.0 \%$ & 201 & Total & $\mathbf{7}$ \\
\hline
\end{tabular}


Table 9: The main cause of accidents

\begin{tabular}{|c|c|c|c|}
\hline The share of total & Number & The subject & Row \\
\hline $30.15 \%$ & 60 & No yield sign & $\mathbf{1}$ \\
\hline $68.33 \%$ & 41 & Disregarding forward & $\mathbf{2}$ \\
\hline $11.05 \%$ & 22 & Tailgating & $\mathbf{3}$ \\
\hline $16.08 \%$ & 32 & Rapidly change directions & $\mathbf{4}$ \\
\hline $6.03 \%$ & 12 & Running red lights & $\mathbf{5}$ \\
\hline $10.05 \%$ & 20 & Crossing the prohibited place & $\mathbf{6}$ \\
\hline $2.01 \%$ & 4 & Inability to control the & $\mathbf{7}$ \\
\hline $4.02 \%$ & 8 & other & $\mathbf{8}$ \\
\hline $100.0 \%$ & 199 & Total & $\mathbf{9}$ \\
\hline
\end{tabular}

Table 10: Culprit in the accident

\begin{tabular}{|c|c|c|c|}
\hline $\begin{array}{c}\text { The share of } \\
\text { total }\end{array}$ & Number & The subject & Row \\
\hline $58.70 \%$ & 118 & The motorcycle driver & $\mathbf{1}$ \\
\hline $37.81 \%$ & 76 & Person & $\mathbf{2}$ \\
\hline $3.48 \%$ & 7 & other & $\mathbf{3}$ \\
\hline $100.0 \%$ & 201 & Total & $\mathbf{4}$ \\
\hline
\end{tabular}

Table 11: Location of accident

\begin{tabular}{|c|c|c|c|}
\hline The share of total & Number & The subject & Row \\
\hline $42.06 \%$ & 98 & Square & $\mathbf{1}$ \\
\hline $27.46 \%$ & 64 & Intersection & $\mathbf{2}$ \\
\hline $6.00 \%$ & 14 & Reservation highway & $\mathbf{3}$ \\
\hline $0.0 \%$ & 0 & Hotline & $\mathbf{4}$ \\
\hline $16.30 \%$ & 38 & Straight path & $\mathbf{5}$ \\
\hline $0.01 \%$ & 19 & other & $\mathbf{6}$ \\
\hline $100.0 \%$ & 233 & Total & $\mathbf{7}$ \\
\hline
\end{tabular}

Table 12: Use of helmet

\begin{tabular}{|c|c|c|c|}
\hline Non-use of helmets & The use of caps & The subject & Row \\
\hline $61.32 \%$ & $38.67 \%$ & The motorcycle driver & $\mathbf{1}$ \\
\hline $89 \%$ & $11 \%$ & Turkish & $\mathbf{2}$ \\
\hline
\end{tabular}

Table 13: The number of casualties and victims

\begin{tabular}{|c|c|c|c|}
\hline The number of victims & The number of injured & The subject & Row \\
\hline 0 & 133 & Bikers & $\mathbf{1}$ \\
\hline 0 & 43 & Turkish & $\mathbf{2}$ \\
\hline
\end{tabular}

\section{Prevention of traffic accidents}

The most important factors that affect the travel safety and reduce accidents on the roads affected include:

- Speed Control 
- Control fatigue

- The use of safety equipment such as seat belts, seats for children, helmet

- The correct driving and handling of a car before driving

\section{Gaps that cause problems statistics are available is as follows: 8.1. lack of education and culture:}

Human factor due to involuntary errors and intentional violations decisive role in the shaping of traffic accidents there. Education and culture can be established, the safety sustainable. Hoare man with teaching methods appropriate to appoint individual and social life, but as long as there is no real belief in the need for change and social phenomena. In front of the train and utilize it shows their strength. Lack of training or inappropriate training, a major cause of the high rate of accidents especially in motorcycle is. A lack of attention from a driver, could lead to the disintegration of families and lives there without support. The public should be educated traffic regulations, especially motorcyclists, to be improved. Education should start from kindergarten level up their children from the beginning of the importance of legal justification.

\subsection{Weak law enforcement:}

In many cases the weakness of law enforcement can be seen, in any society if the law is properly implemented, and with no one willing to do is decide against it. Until, that's in your society allows an offender should not be allowed to trample all. Even in cases where dealing is done, so fragile that the offender will not be affected. When strict certification tests, while driving, the accident must be so severe that the person guilty of the contrary is afraid again.

\subsection{Non-compliance with manufacturing standards:}

As mentioned in the standards, there are still tough domestic production standards. If necessary standards to the extent that otherwise lead to the closure of the manufacturer, the manufacturer does not disobey. But unfortunately it is not only destroyed but also the relationship of all the stringency of doing things will be easier.

\section{Conclusion}

The poor conditions of movement of motorcycles in the streets of the town of Eslamshahr - Saveh Road, which is studied in this paper suggests, need to move seriously on the national level and for most cities. Motorcycle production continued lack of education and poor quality, especially in terms of safety and adverse trends Charts. Continuing education in the region, especially motorcyclists for motorcyclists who for whatever reason have been about rule of law is strongly recommended. The most important points in the city to prevent accidents and to reduce and prevent injury and death from it should be considered as follows:

- Organizing the transport of goods and passengers by motorcycle in Eslamshahr

- Implementation of methods such as restrictions limiting the use of motorcycle speed.

- Lack of certification in a timely replacements for people with a number of traffic violations recorded more than standards in developed countries.

- (D) The body of a third party compulsory insurance of passenger's motorbikes to deliver at least two years.

- The accuracy and speed strictly apply the provisions relating to motorcycle drivers who commit traffic offenses for violations are common.

- Certification with various credit for experienced motorcycle riders and motorcycle riders age 6 months and one year with temporary credit and a maximum of three years. 
- Mandate the use of safety equipment including helmet and gloves and dress shoes motorcyclists by motorcyclists.

- Promotion of view motorcycle, motorcycle paint, and helmet use.

- Commitment to the production of electric motorcycle industry, motorcycle manufacturer.

In general, in order to promote motorcycle safety to form a group to study the material presented in this article were. And the culture of others and modify driving behavior, to study different aspects of the accident that the cases mentioned below, were:

1. The Role of schools and teachers in reducing traffic accidents

2. The pattern of behavior of motorcyclists in traffic accidents

3. To determine the causes of accidents in motorcycle riders

4. Evaluation of the role of design and color of clothes safety Motorcycle Riders.

5. The cause of non-use of helmets in motorcycle riders.

6. The effect of various training programs traffic and other institutions and organizations to reduce traffic accidents motorcycle riders.

7. Risk and high-risk behaviors motorcyclists and their perception of risk.

8. The Role of the media (radio, television, newspaper and ...) in reducing traffic accidents motorcycle riders.

9. The Role of false job street in traffic accidents increased by motorcycle riders.

10. Evaluation of the effect of family in the local culture of different regions of the country, according to the economic, social and cultural rights, and in a motorcycle accident.

\section{References}

1- Statistics collected by the traffic department motorcycle accident.

2- Statistics obtained from the medical examiner's office in Tehran.

3- Tips to increase traffic safety and motorcyclists - Maryam Azimi - Traffic News (36) 1381.

4- Mohammad Bulgarian - traffic rules and regulations of freight traffic rules and regulations set in 1379 Naja Naja. Traffic printing tasks. 